\title{
Effect Study On Middle Phase Microemulsion Displacement System
}

\author{
Keliang WANG ${ }^{1, a}$, Bingling ZHOU ${ }^{1, b}$, Jing $Z_{H A N G}{ }^{1, c}$ and Guoqiang FU ${ }^{1, d}$ \\ ${ }^{1}$ MOE Key Laboratory of EOR Technology, Northeast Petroleum University, Daqing 163318, China \\ awangkl0608@126.com, b18945925390@163.com, '1535949753@qq.com, d282687078@qq.com
}

Keywords: Middle phase microemulsion; Oil recovery; Solubilization; Interfacial tension

Abstract. Middle phase microemulsion flooding is an effective approach to improve reservoir recovery. Using orthogonal experiment, we obtain the preparation of middle phase microemulsion formula of oil displacement system. Scanning respectively SDS concentration, concentration of n-butyl alcohol and $\mathrm{Na}_{2} \mathrm{CO}_{3}$, we get the volume of the phase diagram and dissolve parameters figure. It can be seen: $\mathrm{V}_{\mathrm{o}}=\mathrm{V}_{\mathrm{w}}, \mathrm{SP}_{\mathrm{o}}=\mathrm{SP}_{\mathrm{w}}$, and achieved the best phase system. Contrast middle phase microemulsion in the best and surfactant flooding experiment after water flooding to improve oil recovery, the best middle phase microemulsion has obtained much better effects. The recovery ratio of Berea core by the best middle phase microemulsion and polymer solution system flooding after water flooding was raised about 44.5 percent, and the moisture content down to very low levels.

\section{Introduction}

Microemulsion is comprised of surface, additives and oil/water mixture which is a kind of thermodynamic stability system ${ }^{[1,2,3]}$. According to the circumstance of microemulsion and oil-water phase coexistence, it can be divided into the hypophase, middle-phase and upper-phase. Middle phase microemulsion can greatly improve the displacement efficiency, so middle phase microemulsion flooding provides a very promising tertiary oil recovery technology after water flooding. Middle phase microemulsion can be raised to dissolve in oil but also raised water soluble. when the interfacial tension of middle phase microemulsion and oil-water is equal $\left(\sigma_{\mathrm{mo}}=\sigma_{\mathrm{mw}}\right)$, the interfacial tension of the system $\left(\sigma_{\mathrm{c}}\right)$ is minimum. At this time, the rights of oil and water solubility parameters are equal $\left(\mathrm{SP}_{\mathrm{o}}=\mathrm{SP}_{\mathrm{w}}\right)$, and that of the system is also the biggest ${ }^{[4,5]}$. The mechanism of Microemulsion displacement is very complex, but the key factor lies in the interfacial tension that microemulsion can lower the interfacial tension to $10^{-3} \sim 10^{-4} \mathrm{mN} / \mathrm{m}$, and make the maximum amount of solubilization of crude oil in the salt water ${ }^{[6]}$. The main purpose of study in microemulsion flooding effect is to determine the optimal phase microemulsion formula, and design oil displacement experiment to evaluate formula oil displacement effect, so it provides the basis for further improve oil recovery technology after water flooding.

\section{Experiment conditions}

Experimental materials. Oil phase (kerosene); Formation water (salinity is $3700 \mathrm{mg} / \mathrm{l}$ ); $\mathrm{Na}_{2} \mathrm{CO}_{3}$; n-butyl alcohol; Sodium dodecyl sulfate (SDS). ALC-210.4 electronic balance; EMS-3A Heating magnetic stirrer regularly; $25 \mathrm{ml}$ Several test tube; Alkali type buret; Multifunctional physical simulation experiment device; Core gripper, intermediate container, pressure gauge, ring pump, ISCO trace constant speed pump, etc. Berea core (its water permeability is $\mathrm{K}_{\mathrm{g}}=400 \mathrm{md}$ ).

The orthogonal experimental design. Microemulsion consists of five components: kerosene, formation water, SDS, n-butyl alcohol, $\mathrm{Na}_{2} \mathrm{CO}_{3}$. Fixed oil/water volume ratio of 1:1, we adjust the concentration of SDS, n-butyl alcohol and $\mathrm{Na}_{2} \mathrm{CO}_{3}$, and record Phase volume of microemulsion, residual oil and water. Through the analysis of orthogonal experimental results, thus optimizing phase microemulsion system in the best formula. By analyzing the results, we selected the best formula of microemulsion system.

Winsor phase diagram and dissolve parameters diagram. Fixed oil/water volume ratio of 1:1, we take the specified amount of n-butyl alcohol, $\mathrm{Na}_{2} \mathrm{CO}_{3}$, and a series of different concentrations of SDS solution as surfactant. After fully mixing using a magnetic stirrer, we put it in constant temperature 
box for $10 \mathrm{~h}$ under the condition of $45^{\circ} \mathrm{C}$. When reached phase equilibrium, we record the volume of each phase, and draw phase volume diagram for The surfactant concentration. Using the same method, we draw phase volume diagram for salinity and alcohol concentration Under the condition of fixed other components.

Here we define that solvent parameter is rights to dissolve oil/water volume Unit mass of surfactants:

$$
S P_{W}=\frac{V_{W}}{m_{s}} \quad S P_{O}=\frac{V_{O}}{m_{s}}
$$

Among, $S P_{W}, S P_{O}$ - rights to dissolve water and oil, $\mathrm{g} / \mathrm{ml} ; V_{W}, V_{O}$ - rights to dissolve water and oil volume, $\mathrm{mL} ; m_{s}$ - The quality of the surfactant.

Experimental research on enhanced oil recovery. By conducting the Berea core displacement experiment, We compare oil displacement effect of surfactant/polymer system and middle phase microemulsion/polymer system after water flooding. The surfactant/polymer system consists of the surfactant $(0.3 \mathrm{PV})$ and polymer (the relative molecular weight is $1600 \times 10^{4}, \mathrm{C}_{\mathrm{p}}=1500 \mathrm{mg} / \mathrm{L}, 0.2 \mathrm{PV}$ ). The middle phase microemulsion system/polymer system consists of middle phase microemulsion (0.3PV) and polymer (the relative molecular weight is $1600 \times 10^{4}, \mathrm{C}_{\mathrm{p}}=1500 \mathrm{mg} / \mathrm{L}, 0.2 \mathrm{PV}$ ). The experimental water is obtained from oil reservoir, and the total salinity is $3700 \mathrm{mg} / \mathrm{L}$. The temperature of the thermostat is $45^{\circ} \mathrm{C}$.

\section{Result analyses}

The results analysis of the orthogonal experiment. Through designed the orthogonal experiment, We take the volume difference $(\triangle V)$ from residual oil and residual water phase In the microemulsion system as evaluation indexes, Namely $\left|\mathrm{V}_{\mathrm{o}}-\mathrm{V}_{\mathrm{w}}\right|=\triangle \mathrm{V}$. the smaller $\triangle \mathrm{V}$ is, the closer it gets to the best of microemulsion system.

Table1 The experimental results of the orthogonal test

\begin{tabular}{cccccccc}
\hline No & $\begin{array}{c}\mathrm{C}_{\mathrm{SDS}} \\
(\mathrm{g} / \mathrm{ml}, \%\end{array}$ & $\begin{array}{c}\mathrm{C}_{\text {n-butyl alcohol }} \\
(\mathrm{g} / \mathrm{ml}, \%\end{array}$ & $\begin{array}{c}\mathrm{C}_{\mathrm{Na} 2 \mathrm{CO} 3} \\
(\mathrm{~g} / \mathrm{ml}, \%\end{array}$ & $\mathrm{V}_{\mathrm{o}} / \mathrm{mL}$ & $\mathrm{V}_{\mathrm{m}} / \mathrm{mL}$ & $\mathrm{V}_{\mathrm{w}} / \mathrm{mL}$ & $\triangle \mathrm{V} / \mathrm{mL}$ \\
\hline 1 & 2 & 6 & 2 & 7 & 7.6 & 5.4 & 1.6 \\
\hline 2 & 2 & 7 & 3 & 6.2 & 6.8 & 7 & 0.8 \\
\hline 3 & 2 & 8 & 4 & 6 & 6.6 & 7.4 & 1.4 \\
\hline 4 & 3 & 6 & 2 & 6.6 & 7.4 & 6 & 0.6 \\
\hline 5 & 3 & 7 & 3 & 6.2 & 6.8 & 7 & 0.8 \\
\hline 6 & 3 & 8 & 4 & 6.4 & 7 & 6.6 & 0.2 \\
\hline 7 & 4 & 6 & 2 & 6.4 & 8.4 & 5.2 & 1.2 \\
\hline 8 & 4 & 7 & 3 & 6 & 8 & 6 & 0 \\
\hline 9 & 4 & 8 & 4 & 4.6 & 8.2 & 7.2 & 2.6 \\
\hline
\end{tabular}

From the Table1, if we take $\triangle \mathrm{V}$ as evaluation indexes, the influence factors of the microemulsion system are concentration of n-butyl alcohol, concentration of SDS concentration, and concentration of $\mathrm{Na}_{2} \mathrm{CO}_{3}$ in turn. Finally, the best condition of the system is $\mathrm{C}_{\mathrm{SDS}}=4 \%, \mathrm{C}_{n \text {-butyl alcohol }}=7 \%$, and $\mathrm{C}_{\mathrm{Na} 2 \mathrm{CO} 3}=3 \%$.

Influence of system composition on phase behavior and solubility parameters. Fixed oil/water volume ratio of $1: 1$ in the $\mathrm{SDS} / \mathrm{n}$-butanol/ $\mathrm{Na}_{2} \mathrm{CO}_{3} / \mathrm{kerosene} /$ formation water system under the condition of $45^{\circ} \mathrm{C}$, we adjust the concentration of SDS, n-butyl alcohol and $\mathrm{Na}_{2} \mathrm{CO}_{3}$, and record Phase volume of microemulsion, residual oil and water. Thus we get the phase diagram and dissolve parameters. 

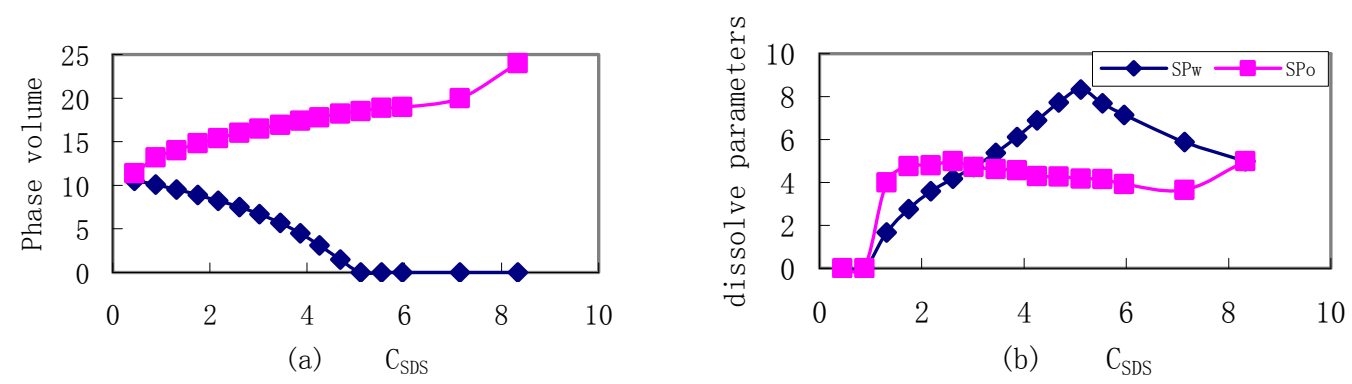

Figure1 Effect of SDS on microemulsion

When surfactant concentration is lower than the critical micelle concentration, the surfactant is mainly used to reduce the interfacial tension by concentration on the oil-water interface. With the increase of surfactant concentration, it is beginning to form micelles in water. In this way, there will be a part of the oil in nonpolar micelle core. As can be seen from the Fig. 1 (a) and (b), the $\mathrm{SP}_{\mathrm{w}}$ and $\mathrm{SP}_{\mathrm{o}}$ are rapidly increasing with the increase of number of microemulsion gathered when SDS concentration higher than $0.4 \%$. When the concentration is $3 \%$, the $\mathrm{SP}_{\mathrm{w}}$ is equal to the $\mathrm{SP}_{\mathrm{o}}\left(\mathrm{SP}_{\mathrm{w}}=\right.$ $\mathrm{SP}_{\mathrm{o}}$ ), and $\triangle \mathrm{V}=0$. Then the system is the best.
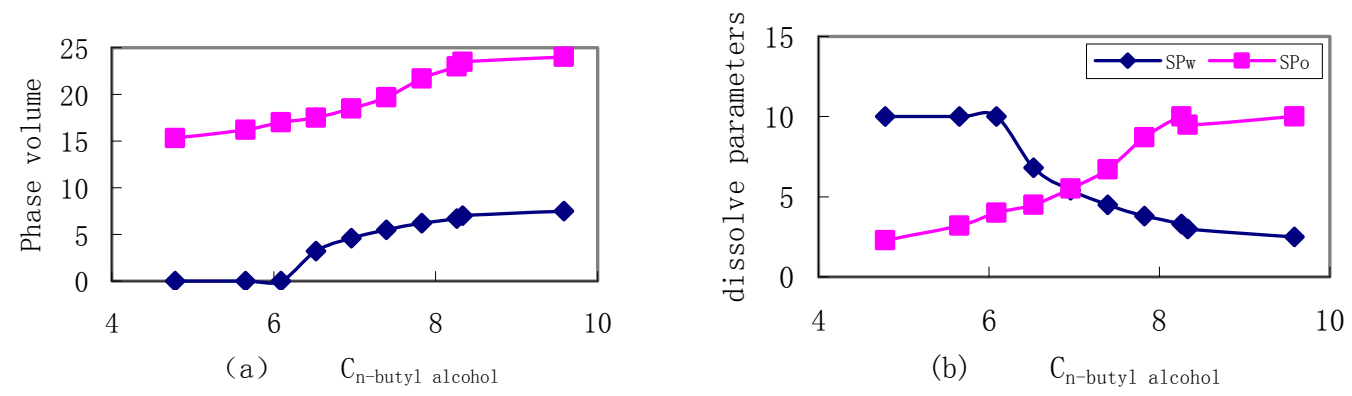

Figure2 Effect of n-butanol on microemulsion

In the process of microemulsion formation, Part of the alcohol is involved in formation interface composite membrane, and Part is distributed in the oil phase and water phase which It makes two phase properties improved. As can be seen from the Fig. 2 (a) and (b), it began to form in middle phase microemulsion when n-butyl alcohol concentration is $6 \%$. This is because the density of charge for composite membrane is dropped with the increase of n-butyl alcohol concentration.Between droplets is easy to approach and coalescence, which makes the strength of the composite membrane increased. And $\mathrm{SP}_{\mathrm{o}}$ is increased, the enrichment of microemulsion phase separated from the hypophase is formed in middle-phase. When the concentration is greater than $7.8 \%, \mathrm{n}$-butyl alcohol and SDS is began to pour into oil phase. At this time, the middle-phase microemulsion are destroyed, formed the upper-phase microemulsion. The best alcohol concentration from $\mathrm{SPw}$ and $\mathrm{SP}_{\mathrm{o}}$ intersection point of the Fig. 2 (b) and the results analysis of the orthogonal experiment are basically identical.
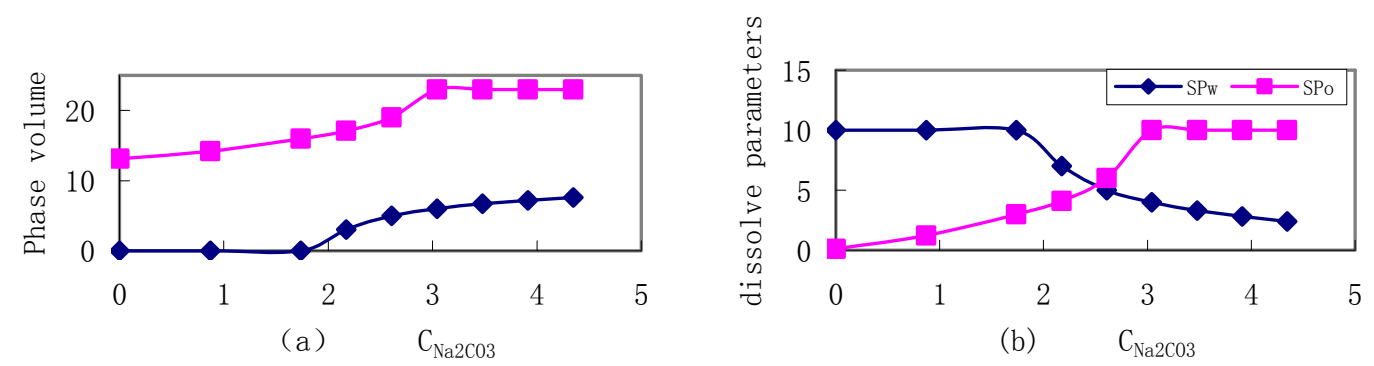

Figure3 Effect of $\mathrm{Na}_{2} \mathrm{CO}_{3}$ on microemulsion 
As can be seen from the Fig. 3 (a), the microemulsion is the hypophase when the concentration of $\mathrm{Na}_{2} \mathrm{CO}_{3}$ is less than $1.7 \%$. with the increase of $\mathrm{Na}_{2} \mathrm{CO}_{3}$ concentration, the number of microemulsion gathered is enlarged, and oil soluble capacity are also increased. Because bethe repulsive force between the droplets is reduced, microemulsion droplets is more conducive to gather, So that the enrichment of microemulsion phase separated from the hypophase is formed in middle-phase. When the concentration is higher than $3 \%$, the amount of surfactant into the oil phase from the precipitation in microemulsion is increased, and the middle-phase microemulsion are destroyed, formed the upper-phase microemulsion. Fig. 3 (b), curve of oil and water phase solubility parameter is the intersection with $\mathrm{SP}_{\mathrm{w}}=\mathrm{SP}_{\mathrm{o}}=\mathrm{SP}^{*}$ and $\triangle \mathrm{V}=0$, which is consistent with the results analysis of orthogonal experiment analysis.

Displaced efficiency. On the basis of filtered optimal middle phase microemulsion oil displacement system, the oil displacement effect of different systems was studied. The used displacing systems are respectively optimal middle phase microemulsion system $(4.34 \% \mathrm{SDS} / 6.95 \%$ n-butyl alcohol $/ 2.17 \%$ $\mathrm{Na}_{2} \mathrm{CO}_{3}$ /formation water/kerosene) and surfactant system (4.34\%SDS/formation water). The experimental results are shown in Table 2. From the experimentation results, it is found that the displacement effect of optimal middle phase microemulsion system is better, the recovery after water flooding is $44.5 \%$.

Table2 The experimental results of the displacement test

\begin{tabular}{ccccccc}
\hline Core & Formula & $\begin{array}{c}\text { Porosity } \\
/ \%\end{array}$ & $\begin{array}{c}\text { Oil saturation } \\
/ \%\end{array}$ & $\begin{array}{c}\text { Water } \\
\text { flooding } \\
\text { recovery } / \%\end{array}$ & $\begin{array}{c}\text { Chemical } \\
\text { flooding } \\
\text { recovery } / \%\end{array}$ & $\begin{array}{c}\text { Final } \\
\text { recovery } \\
/ \%\end{array}$ \\
\hline $1-1$ & Surfactant + polymer & 20.03 & 70.46 & 39.7 & 34.4 & 74.1 \\
\hline $1-2$ & $\begin{array}{c}\text { middle phase } \\
\text { microemulsion+ } \\
\text { polymer }\end{array}$ & 21.56 & 67.92 & 38.8 & 44.5 & 83.3 \\
\hline
\end{tabular}

In the core displacement experiment, one of the important displacement mechanisms is forming oil wall. Middle phase microemulsion will reduce oil - water interfacial tension and the deformation resistance of oil droplets which make oil droplets pass through the cervical mouth more easily and then aggregate to form oil wall. Meanwhile oil wall travel through core, it can gather the other remaining oil. This behavior likes rocking snowball, therefore it can receive high recovery. when the injected slug of middle phase microemulsion - polymer system, the oil wall without water is emerged in the core outlet. The chemical flooding eventually improved recovery $44.5 \%$ and residual oil saturation reduced to $16.7 \%$.

After forming oil wall, residual oil saturation is reduced and mobility ratio changes to less than 1 . This displacement process is similar to piston-like displacement and thereby reduces moisture content dramaticlly.

\section{Conclusions}

Make the volume difference between residual oil phase and residual water phase in microemulsion system as evaluation index, use orthogonal experiment to get the formula of optimal middle phase microemulsion system is: $\mathrm{C}_{\mathrm{SDS}}=4.34 \%, \mathrm{C}_{\mathrm{Butanol}}=6.95 \%, \mathrm{C}_{\mathrm{Na} 2 \mathrm{CO} 3}=2.17 \%$;

Use Winsor phase-graph method to respectively scan the concentration of SDS, n-butyl alcohol and $\mathrm{Na}_{2} \mathrm{CO}_{3}$. It can be seen that with the increase of SDS concentration the volume of middle phase is more and more big and finally the single phase is formed. With the increase of n-butyl alcohol and $\mathrm{Na}_{2} \mathrm{CO}_{3}$ concentration, microemulsion transforms from bottom phase, middle phase to top phase. Dissolve parameters SPw and SPo intersect at optimal alcohol/salt concentration. The optimal 
concentration of SDS, $n$-butyl alcohol and $\mathrm{Na}_{2} \mathrm{CO}_{3}$ received from scanning is the same as the results of orthogonal experiment.

Core displacement experiment shows that, the preparative optimal middle phase microemulsion system can improve oil recovery $44.5 \%$ after water flooding. Residual oil saturation is reduced to $16.7 \%$ eventually and meanwhile the moisture content is downgraded dramatically.

\section{Acknowledgements}

This work was financially supported by National Science and Technology Major Project (2011ZX05009).

\section{References}

[1] Winsor PA. Solvent Properties Amphiphilic Compounds, London: Butterworth's. (1954), p.68

[2] Ganzuo Li, Rong Guo. Edtied by Petroleum Industry Press, (1995), in press. In Chinese

[3] Yongmei Chen, Hanre Wang. Journal of Chemical Physics, (2000), 16 (8): 724 728. In Chinese

[4] Rong Guo, Xun Wei and Tianqing Liu. Colloids and Surfaces A, (2006), 277, 59 62. In Chinese

[5] Tianqing Liu, Jianxin Xu and Rong Guo, Colloid Polym. Sci., (2006), 284, 788 794. In Chinese

[6] Hanqing Wang, Jingcheng Hao and Runhua Lu. Chinese Science (B), (1997), 27 (2): 131 132. In Chinese 